\title{
Impact of a Medium Flow Maldistribution on a Cross-Flow Heat Exchanger Performance
}

\author{
Tomasz Bury \\ Silesian University of Technology \\ Poland
}

\section{Introduction}

\subsection{Characteristics of the problem}

The plate exchangers (with the mixed current) and the finned cross-flow heat exchangers, which core has the form of a bunch of pipes with flat plate ribs, have the most important meaning among the currently applied heat exchangers with extended surface. These heat exchangers are usually used for heat transfer between a liquid flowing inside the tubes and a gaseous medium flowing outside the tubes, on the ribs side. Small size, low weight and a high efficiency determine the strong position of such devices. Compact ribbed heat exchangers are commonly used in thermal technique, refrigeration, air-conditioning and automotive industry.

A typical thermodynamic analysis of a cross-flow heat exchanger is usually aimed in determination of the heat transfer surface for the desired design and its capacity. There are several simplifying assumptions made during such calculations, for example neglecting of the heat losses to the environment, uniform flow of media through the exchanger, heat transfer coefficients determined for the average temperatures. These assumptions are fulfilled very rarely in reality and of course it affects the analytical results to some degree.

The subject of this work is evaluation of the impact of a non-uniform flow of media (or flow maldistribution) on very popular finned cross-flow heat exchangers performance. The reasons for such maldistribution occurring in an exchanger include the layout of the exchanger with respect to other components in the system, effects of manufacturing tolerances, the design of the flow circuits in the exchanger and the design of the inlet and outlet headers. In some instances, the maldistribution could also be induced due to temperature effects. These factors become even more critical when the exchangers are applied in compact designs which involve a tortuous flow path for both the fluid streams. This situation may lead to some losses in the total heat flow rates transferred in the heat exchanger and affects its thermal efficiency. There is therefore the obvious question: to what extent inequality of media flows worsens effects of the heat exchanger?

One of the most important parameters describing such heat exchangers is the heat transfer coefficient on the gas side. Usually, this coefficient is determined as an average value for the whole heat transfer surface. This is of course another simplification. Beside of these simplifying assumptions, a variety of constructions being applied causes significant 
problems with determination of this coefficient. The problem is additionally complicated by a non-uniform flow of a gas. This flow maldistribution induces also some non-uniform distribution of the heat transfer coefficient. So, another important question is how this situation influences the thermodynamic analysis where the average value of this parameter is applied usually?

\subsection{Review of previous studies}

The question of a non-uniform flow of media through heat exchangers is not a new problem. It is the subject of investigations for many years. Results, especially taken from older works, are sometimes very unambiguous.

The first one investigation referred to the heat exchangers with unequal flow of agents was performed at the Institute of Thermal Technology of the Silesian University of Technology (ITT SUT) for gaseous mediums and they had only computational form (HanuszkiewiczDrapała, 1996). Investigations of the gas-liquid type cross-flow heat exchanger have been conducted at the ITT SUT since a few years to evaluate an influence of a non-uniform gas inlet on the exchanger functioning (Piątek, 2003). A range and form of the air inflow nonuniformity have been determined on the special testing station - see Fig.1 in the next section. Configuration of the measuring system of the test station allows determining the air velocity and temperature distribution at the heat exchanger inlet and outlet. This test station, in its original arrangement, allowed only for "cold" experiments, it means without presence of the hot medium. Thus, the influence of the measured non-uniformity has been assessed by means of numerical simulations performed by the computer code called HEWES - worked out for thermal analyses of the considered heat exchanger. R. Piątek in his work (Piątek, 2003) concludes that the maldistribution of the air inlet to the investigated car cooler may significantly influence the effectiveness of the heat exchanger.

An unique feature of the investigations realized at the ITT SUT is experimental consideration of the air flow non-uniformity. Similar heat exchangers have been investigated by D. Taler with co-workers (Taler, 2002; Taler and Cebula, 2004) by means of physical experiments and numerical simulations too. Very good compliance of experimental and numerical results has been achieved, but the problem of the non-uniform agents flow is neglected and this fact simplified experimental measurements.

Many researches considering the problem of the non-uniform flow of media have been realized only numerically. Authors of (Ranganayakulu et al., 1997) have simulated the plate fin heat exchanger using the finite elements method and found out that the influence of the non-uniformity of the liquid flow may have significant meaning in some work regimes. A very significant drop of the heat exchanger efficiency has been also observed by authors of (Andrecovich and Clarke, 2003). The opposite results have obtained authors of (Nair et al., 1998) and (Lee and Oh, 2004). Numerical simulations realized for a rotary heat exchanger in the first work and optimization procedure presented in the second one have not shown significant dependence on the agents flow non-uniformity.

There are many works, both experimental and numerical, considering only the flow maldistribution impact on hydraulic efficiency of heat exchangers. Anjun with his coworkers investigated the influence of headers configuration on the non-uniformity range (Anjun et al., 2003). The numerical results presented in (Wen and $\mathrm{Li}, 2004$ ) indicate that the 
improved header configuration can effectively improve the performance of a fin-and-tube type heat exchanger. An experimentally determined flow maldistribution for a plate finand-tube heat exchanger has been also described in (Hoffmann-Vocke et al., 2009), but the authors have not considered its impact on the heat exchanger thermal efficiency. This group of authors has presented in (Hoffmann-Vocke et al., 2011) even more detailed, but still only hydraulic analysis of the considered heat exchanger.

Experimental analyses considering maldistributions of the agents flow through the heat exchangers and dealing with thermodynamic effects are rare. A. Mueller in (Mueller, 1987) concludes about major significance of flow maldistributions for heat exchangers performance. Based on the study of gross flow maldistribution in an experimental electrical heater the paper (Lalot et al., 1999) presents the effect of flow non-uniformity on the performance of heat exchangers. The original fluid distribution is applied to heat exchangers (condensers, counterflow and cross-flow heat exchangers), and it is shown that gross flow maldistribution leads to a loss of effectiveness of about $7 \%$ for condensers and counterflow heat exchangers, and up to $25 \%$ for cross-flow exchangers. Similar effects have been observed by the authors of (Luo et al., 2001) indicate that the non-uniformity influences the efficiency of the heat exchangers to a large extent. Berryman and Russell have studied flow maldistribution across tube bundles in air-cooled heat exchangers (Berryman and Russel, 1987). Their experimental results have detected thermal degradation up to $4 \%$, which is much less than in previously cited works. The authors of (Meyer and Kröger, 1998) concluded about minor - up to $5 \%$ - effects of this phenomenon also.

Another group of investigations deals with evaporators and condensers, applied in airconditioning and refrigeration. The effects of maldistribution in fin-tube heat exchangers, which takes place on the air-side through the fin passages as well as on the liquid side in the tube circuits, have been investigated by several researchers, for example (Fagan, 1980; Chwalowski et al. 1989; Lee and Domanski, 1997; Aganda et al. 2000). The findings of these works have indicated dependence of the degradation on the mean and standard deviation of the flow maldistribution profile.

A very complex research has been realized by teams from Indian Institute of Technology Madras and Lund University of Technology. These works concern plate-type heat exchangers. The numerical model of a one-pass plate heat exchanger has been elaborated first for hydraulic analyses of a flow maldistribution impact (Shrihari et al., 2005) and next it was arranged for multi-pass units (Shrihari and Das, 2008). An experimental investigation has been also carried out to find the flow and the pressure difference across the port to channel in plate heat exchangers (Rao et al., 2006). More recently this research team realized thermal analysis also. The single-blow transient test technique based on axial dispersion model was proposed for the determination of both heat transfer coefficient and axial dispersion coefficient in plate heat exchangers. The experimental analysis presented in (Shaji and Das, 2010) deals with the effect of flow maldistribution on the transient temperature response for U-type plate heat exchangers. The experiments are carried out with uniform and non-uniform flow distributions for various flow rates and two different numbers of plates.

According to (Li-Zhi, 2009) the inlet and outlet duct geometry in an air to air compact heat exchanger is always irregular. Such duct placements usually lead to a non-uniform flow distribution on core surface. The author used a CFD model to predict the flow distribution 
and next calculated the heat exchange effectiveness and the thermal performance deterioration factor with finite difference scheme. Experiments were performed to validate the flow distribution and heat transfer model. The results indicate that when the channel pitch is below $2.0 \mathrm{~mm}$, the flow distribution is quite homogeneous and the thermal deterioration due to flow maldistribution can be neglected. However, when the channel pitch is larger than $2 \mathrm{~mm}$, the maldistribution is quite large and a $10-20 \%$ thermal deterioration factor could be found.

This literature review of the selected positions shows, as already mentioned, that the problem of the non-uniform fluid inflow to the heat exchangers has been the subject of many computational and experimental investigations, but the results obtained are unambiguous in terms of thermal performance. Many investigations are limited to the hydraulic analysis only and they deal with liquid-liquid type heat exchangers. Most researchers are consistent in finding that the non-uniformity of the flow significantly strikes the hydraulic efficiency of heat exchangers. Thermal analyses refer first of all to the heat exchanger effectiveness, but they are not very numerous. It is lack of complete investigations of the finned cross-flow heat exchangers of the gas-liquid type with unequal inflow of the agents, especially of unequal inflow of the gas.

\subsection{Aim and scope of presented studies}

The degradation effects of flow maldistribution on the performance of a heat exchanger are well-known. Not only does the thermal performance decrease but the fluid pressure drop across the exchanger core also increases simultaneously. Analyzing the results of (Piątek, 2003) the obvious question has appeared: how reliable are these results? The HEWES code validation procedure has to be carried out in order to answer this question. It became possible after modernization of the experimental rig and installation of the hot water supply module. In (Bury et al., 2007b) there have been presented the only initial results obtained by use of the modified testing station, and the results of initial and detailed validation and sensitivity analysis have been presented in (Bury et al., 2008a)) and (Bury et al., 2008b). Significant differences have been recorded between experimental and numerical data after the initial validation of the model. Minor changes have been put into the code and the validation procedure was then repeated with usage of the infra-red thermography measurements results also. The last stage of the research was the sensitivity analysis. This analysis has shown that the heat transfer coefficient from ribbed surfaces to a gas may be a reason for recorded discrepancies between numerical and experimental results. An additional testing station, in the lab-scale, has been designed and constructed in order to check the numerical procedure responsible for determination of the heat transfer coefficient from the ribs to the gas. The papers (Bury et al., 2009a; Bury and Składzień,2010) and recently also (Składzień and Bury, 2011) present results of this analysis.

Applying the validated version of the HEWES code and modified testing station the analysis of the above mentioned car cooler has been repeated and the results allowed to sustain the conclusions withdrawn by Piątek - the air inflow maldistribution may significantly affect the heat exchanger performance (Bury et al., 2009b).

The following questions have emerged after analysis the experience gained so far: 
- $\quad$ are own results consistent with data published by other authors stating an important meaning of the flow maldistribution (considering the range of observed heat exchanger efficiency drop)?

- $\quad$ are these results repeatable?

The whole analytical procedure (experiments and numerical simulations) has been performed for three cross flow heat exchangers with different ribbing structure in order to answer these questions. The experimental and numerical procedures are presented in this chapter, as well as the most important results and conclusions.

\section{Experimental investigations}

\subsection{Test station}

The test station consists of two main modules: the air supply module (see Fig. 1) and the hot water supply module (Fig. 2). The air supply module originally was a special testing station constructed during realization of the project (Piątek, 2003) for determination of a form and scope of the air inflow non-uniformity.
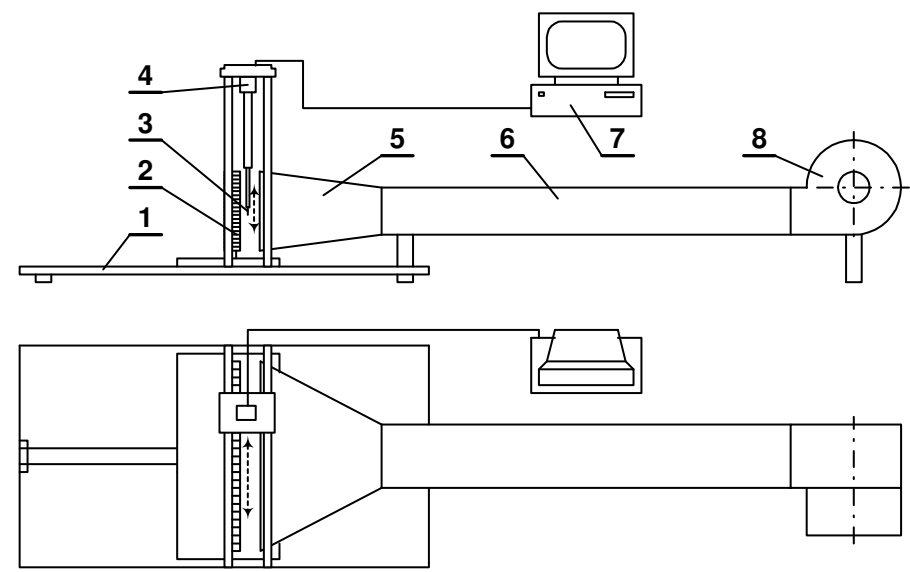

Fig. 1. Test station - the air supply module (1 - support plate, 2 - heat exchanger, 3 thermoanemometric sensor, 4 - measuring probe, 5 - diffuser, 6 - channel, 7 - control computer, 8 - fan).

The air is supplied by the radial fan of the maximum capacity of $6900 \mathrm{~m}^{3} / \mathrm{h}$. The fan capacity can be controlled by the throttling valve installed before the fan. Then the air flows through the $1.7 \mathrm{~m}$ long channel (rectangular cross-section 190x240 mm). The channel ends with the filter section. Usually this section is empty and only during special tests filters having the form of wire nets or perforated metal sheets are used. Actually, filter is not a good word describing the purpose of these elements - they are installed in order to make the air flow more uniform. The diffuser dimensions have been fit to the first examined heat exchanger: they are $280 \times 490 \mathrm{~mm}$.

The main element of the measuring system is the V1T-type thermoanemometric sensor installed onto the measuring probe which shifting is controlled by a computer. It allows 
determining velocity and temperature fields of the air at the exchanger's inlet and outlet. The measuring probe moves in a clit cut out in the upper wall of the diffuser. The clit is seal up with a soft insulating foam. Unfortunately, such a solution is the reason of some air leakage. As the thermoanmenometric sensor is a very fragile instrument its contact with walls and other structures should be prevented. There are $20 \mathrm{~mm}$ wide margins left on the all sides and the probe movement plane is placed $25 \mathrm{~mm}$ in front of the heat exchanger's inlet cross-section. Signals from the sensor are gathered by the FMC 921 control card and send to the computer where they are analysed.

The original testing station has been modified and the hot water supply module was installed. Water is heated up to the desired temperature (up to $95^{\circ} \mathrm{C}$ ) by the electric heater. The water circulation is forced by the pump and its flow rate can be regulated by the control valve. The flow rate is measured by the rotameter and the K-type thermocouples ( $\mathrm{NiCr}-$ $\mathrm{NiAl}$ ) measure its temperature at the inlet and outlet of the heat exchanger.

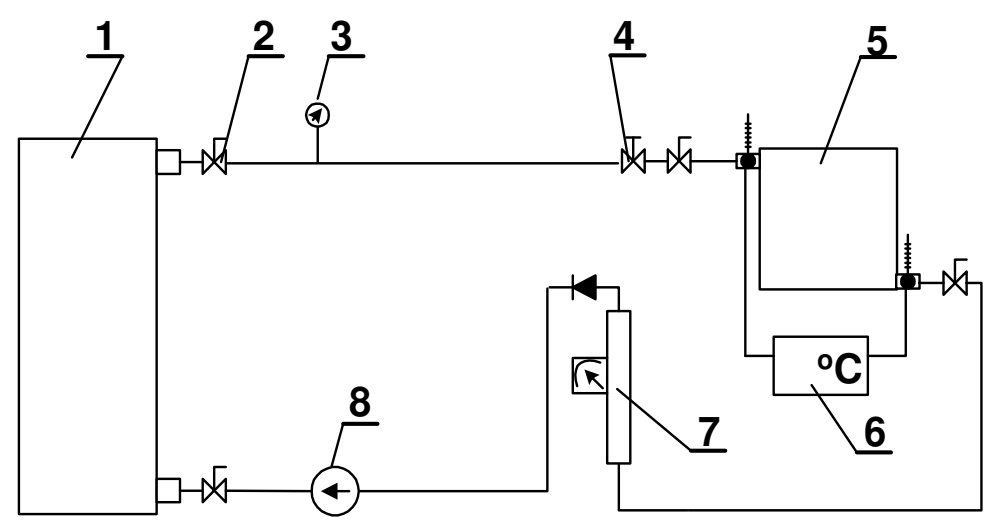

Fig. 2. Test station - the hot water supply module (1 - electric heater, 2 - cut-out valve, 3 manometer, 4 - control valve, 5 - heat exchanger, 6 - temperature measuring system, 7 flow meter, 8 - pump).

The measuring system allows for acquisition of the following parameters at the moment: total air volumetric flow, the water mass flow rate, inlet and outlet water temperature, distribution of the air velocity and temperature at the inlet and outlet of the heat exchanger.

\subsection{Procedures of measurements and experimental data analysis}

The air temperature and velocity distributions measurement need the measuring task to be defined in the form of an input file for the program controlling the measuring probe's work. The trajectory of the probe's shifting is determined by location of measuring nodes. There are two ways for realizing the measurements: applying the spiral-type measuring mesh or the regular-type mesh. These two types of measuring meshes are shown in Fig. 3. The first one is usual while determining the form and scope of the air inlet non-uniformity. Data obtained by use of the regular mesh are more convenient for the complete thermodynamic analysis. Such mesh divides the whole measuring cross-section into identical rectangles and the measuring nodes are located in the middle of each rectangle. 

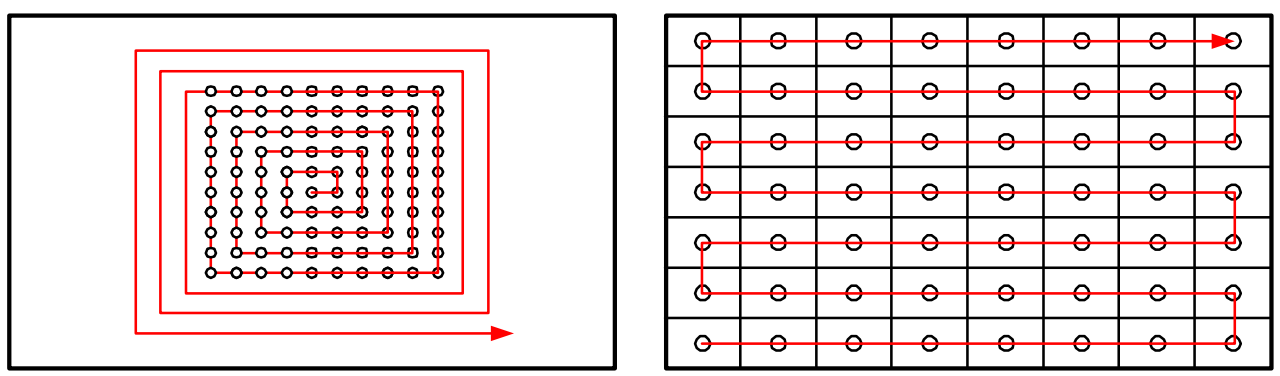

- measuring nodes

Fig. 3. The idea of the spiral-type (left) and regular-type measuring meshes and trajectories of the measuring probe movement.

The time constant of the measurement and the number of measurements realized in each node should be entered in the file. The data are acquired with the maximum frequency allowed by the hardware (CPU clock). So, assuming a $100 \mathrm{~Hz}$ frequency and $0.5 \mathrm{~s}$ time constant there would be 50 samples obtained for the given measuring node. The results are analysed online and the output file contains the average values with their standard deviations for each measuring node, considering both velocity and temperature of the air.

A higher resolution of the results (velocity and temperature distributions) can be achieved by making the measuring meshes more dense. Definition of the measuring mesh needs some optimization between resolution of results and time of measurement, and the aim of measurement as well as the heat exchanger structure should be also taken into account.

A regular measuring mesh of 196 nodes has been used for measurements realized in this work. The measuring program has been started after the steady state conditions were achieved.

Three parameters are assumed as independent and may be set by a researcher: the air and water flow rates and the inlet water temperature.

The cooler heat capacity has been determined as the heat flow rate transferred in the exchanger computed from the air and the water side. Obvious relationships describing the medium enthalpy decrease (increase) have been used:

$$
\begin{gathered}
\dot{Q}_{a}=\dot{V}_{a} \cdot \rho_{a} \cdot c_{p a} \cdot\left(t_{a, \text { out }}-t_{a, \text { in }}\right) \\
\dot{Q}_{w}=\dot{V}_{w} \cdot \rho_{w} \cdot c_{p w} \cdot\left(t_{w, \text { in }}-t_{w, \text { out }}\right)
\end{gathered}
$$

The air density has been calculated using the ideal gas law for the absolute pressure and the air average temperature at the inlet to the exchanger. The density of water has been assumed according to thermodynamic tables for the outlet temperature.

The water enthalpy drop has been used for calculations of the heat flow rates because of more accurate measurement of the water flow. 


\subsection{Analysed heat exchanger types}

The investigations accomplished in this work deal with the ribbed cross-flow heat exchangers of the gas-liquid type. There were three water coolers investigated during realization of this work (see Fig. 4):

HE-1 - typical car cooler (Skoda Favorit 135L) with the core having the form of 2 rows pipe bundle (15 cylindrical pipes ribbed with the plate fins in each row, 380 fins on each pipe); aluminium,

HE-2 - the cross-flow heat exchanger made by GEA Heat Exchangers Company with the core made of 10 rows of elliptical pipes ribbed with the plate fins (175 on each pipe); steel,

HE-3 - the cross-flow heat exchanger made by GEA Heat Exchangers Company with the core having the form of 2 rows pipe bundle ( 81 fins on each pipe in the first row and 140 fins on each pipe in the second row); steel.

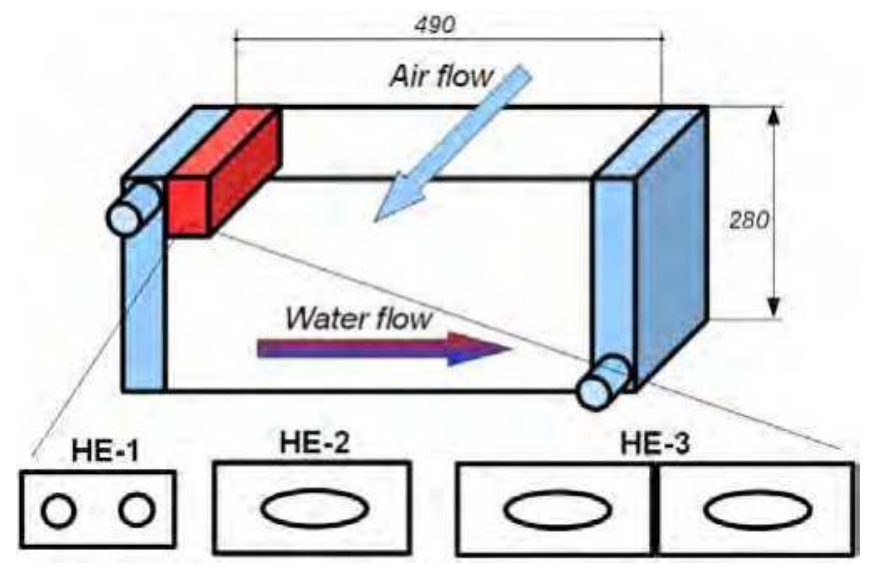

Fig. 4. General sketch of the heat exchangers under consideration and the recurrent elements of three versions of the heat exchangers

\subsection{Selected experimental results}

There were six measuring series carried out for each of the heat exchangers under consideration. The distributions of the air velocity and temperature are one of the most interesting results that may be achieved on the described testing station. These distributions are very important because they allow evaluating the air inflow maldistribution range and form. Sample distributions obtained for the HE-1 heat exchanger are shown in Figs. 5 and 6. These results have been obtained with the total air flow rate of $1.556 \mathrm{~m}^{3} / \mathrm{s}$, the water flow rate of $4.5 \cdot 10^{-4} \mathrm{~m}^{3} / \mathrm{s}$ and the water temperature set on the boiler in $50^{\circ} \mathrm{C}$.

The form and scope of the air inlet non-uniformity depend on the fan capacity, as shown in Fig. 7. This observation, recorded in (Piątek, 2003) and (Bury et al., 2007a) has been confirmed during actual tests and, moreover, some dependence on the heat exchanger has been also noticed. So, it would be better to say that these parameters depend on the piping and ribbing structures in this certain case. 
An attempt for systemizing this non-uniformity has been undertaken in (Malinowski, 2008). The numerical analysis has proved that the reason of the observed air inflow maldistribution is the radial fan. Unfortunately, attempts to describe the measured inequality by using mathematical functions have failed. For this reason, data on the nonuniformity are included in the calculations in tabulated form using rows. This extends the calculation time slightly, but on the other hand allows for accurate recognition of this phenomenon.

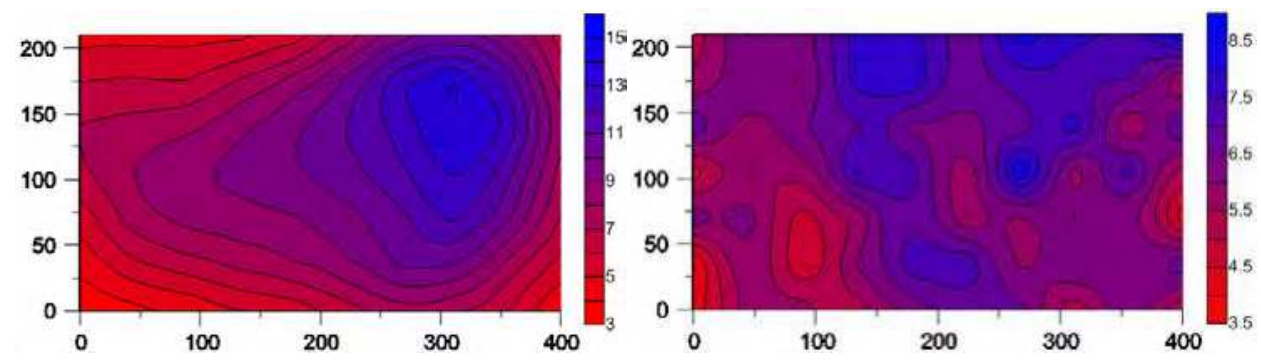

Fig. 5. Distribution of the air velocity at the inlet (left) and outlet (right) cross-sectional flow area $(210 \mathrm{~mm} \times 400 \mathrm{~mm})$ of HE-1/1 measurement, $\mathrm{m} / \mathrm{s}$.

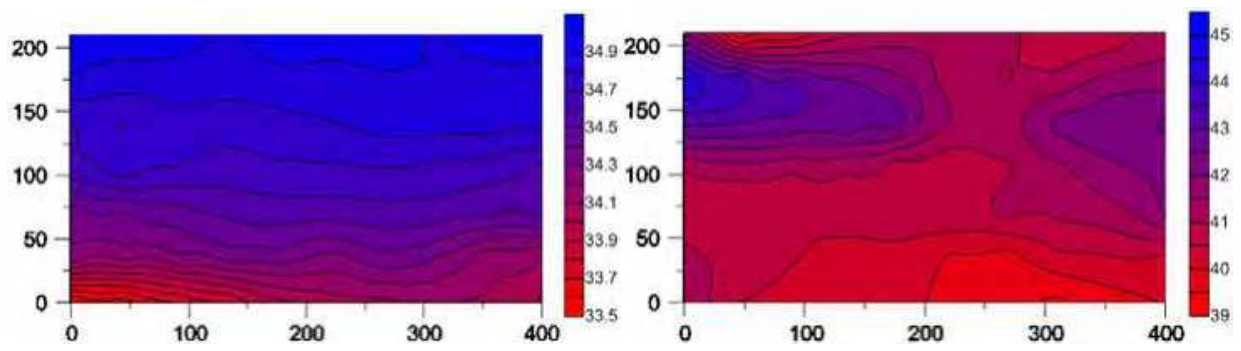

Fig. 6. Distribution of the air temperature at the inlet (left) and outlet (right) cross-sectional flow area $(210 \mathrm{~mm} \times 400 \mathrm{~mm})$ of $\mathrm{HE}-1 / 1$ measurement, ${ }^{\circ} \mathrm{C}$.

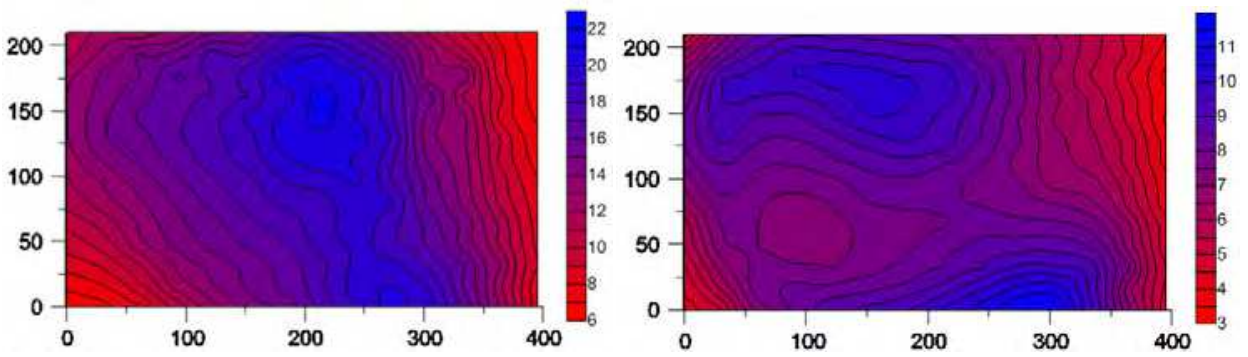

Fig. 7. Distribution of the air velocity at the inlet cross-sectional flow area $(210 \mathrm{~mm} \times 400 \mathrm{~mm})$ of HE-2/1 measurement (left - without throttling) and of HE-3/4 measurement (right maximum throttling), $\mathrm{m} / \mathrm{s}$.

Presented in Figs. 5-7 distributions of velocity and temperature of the air were drawn as viewed from the outlet of the heat exchanger. 


\begin{tabular}{|l|l|l|l|l|l|l|}
\hline $\begin{array}{l}\text { Measurement } \\
\text { No. }\end{array}$ & $\begin{array}{l}\dot{V}_{a} \\
\mathrm{~m}^{3} / \mathrm{s}\end{array}$ & $\begin{array}{l}\dot{V}_{w} \\
\mathrm{~m}^{3} / \mathrm{s}\end{array}$ & $\begin{array}{l}\mathrm{t}_{\mathrm{B}}{ }^{(1)} \\
{ }^{\circ} \mathrm{C}\end{array}$ & $\begin{array}{l}\mathrm{t}_{\mathrm{w}, \text { in }} \\
{ }^{\circ} \mathrm{C}\end{array}$ & $\begin{array}{l}\mathrm{t}_{\mathrm{w}, \text { out }} \\
{ }^{\circ} \mathrm{C}\end{array}$ & $\begin{array}{l}\dot{Q}_{w} \\
\mathrm{~kW}\end{array}$ \\
\hline HE-1/1 & 1.556 & $4.5 \cdot 10^{-4}$ & 50 & 49.8 & 43.9 & 11.03 \\
\hline HE-1/2 & 1.556 & $4.5 \cdot 10^{-4}$ & 70 & 68.9 & 56.7 & 22.61 \\
\hline HE-1/4 & 1.556 & $4.5 \cdot 10^{-4}$ & 90 & 86.4 & 67.9 & 34.08 \\
\hline HE-1/5 & 1.083 & $4.5 \cdot 10^{-4}$ & 50 & 49.7 & 44.5 & 9.72 \\
\hline HE-1/6 & 1.083 & $4.5 \cdot 10^{-4}$ & 70 & 69.2 & 58.7 & 19.42 \\
\hline HE-2/1 & 1.083 & $4.5 \cdot 10^{-4}$ & 90 & 88.0 & 72.2 & 29.11 \\
\hline HE-2/2 & 2.04 & $4.5 \cdot 10^{-4}$ & 50 & 48.2 & 42.8 & 10.07 \\
\hline HE-2/3 & 2.04 & $4.5 \cdot 10^{-4}$ & 70 & 69.6 & 62.0 & 14.08 \\
\hline HE-2/4 & 2.04 & $4.5 \cdot 10^{-4}$ & 90 & 90.2 & 79.5 & 19.58 \\
\hline HE-2/5 & 1.063 & $4.5 \cdot 10^{-4}$ & 50 & 48.0 & 45.6 & 4.48 \\
\hline HE-2/6 & 1.074 & $4.5 \cdot 10^{-4}$ & 70 & 68.5 & 62.0 & 12.04 \\
\hline HE-3/1 & 2.033 & $4.5 \cdot 10^{-4}$ & 90 & 89.8 & 79.0 & 19.76 \\
\hline HE-3/2 & 1.876 & $4.5 \cdot 10^{-4}$ & 50 & 49.3 & 42.7 & 12.39 \\
\hline HE-3/3 & 1.876 & $4.5 \cdot 10^{-4}$ & 70 & 69.1 & 59.8 & 17.31 \\
\hline HE-3/4 & 1.877 & $4.5 \cdot 10^{-4}$ & 90 & 87.8 & 74.6 & 24.08 \\
\hline HE-3/5 & 1.052 & $4.5 \cdot 10^{-4}$ & 50 & 50.1 & 47.1 & 5.51 \\
\hline HE-3/6 & 1.052 & $4.5 \cdot 10^{-4}$ & 70 & 69.6 & 61.6 & 14.81 \\
\hline
\end{tabular}

(1): the temperature set at the electric boiler outlet

Table 1. Results of measurements.

The results of the measurements for the three considered heat exchangers are summarized in Table 1. All the measurements have been repeated for three times in order to verify repeatability of results. Presented in the last column heat flow rates, of course, refer to the conditions of non-uniform air flow. In order to determine the impact of this inequality on the efficiency of considered heat exchangers in the next stage the computational analysis was carried out. The measured inlet media parameters were used as input for calculations.

\section{Computational analyses}

\subsection{Mathematical model of the heat exchanger}

The mathematical model of the considered heat exchanger has been worked out taking into account the following simplifying assumptions (only most important):

- steady state conditions,

- one-dimensional media flow,

- radiation is neglected,

- heat losses are neglected,

- heat flow is normal to a boundary,

- real rib is replaced with a round or a plate-elliptic rib of the same surface.

It has been also assumed that the air inflow is non-uniform and the water inflow may be non-uniform. An influence of temperature on thermal properties of the agents has been taken into account too. 


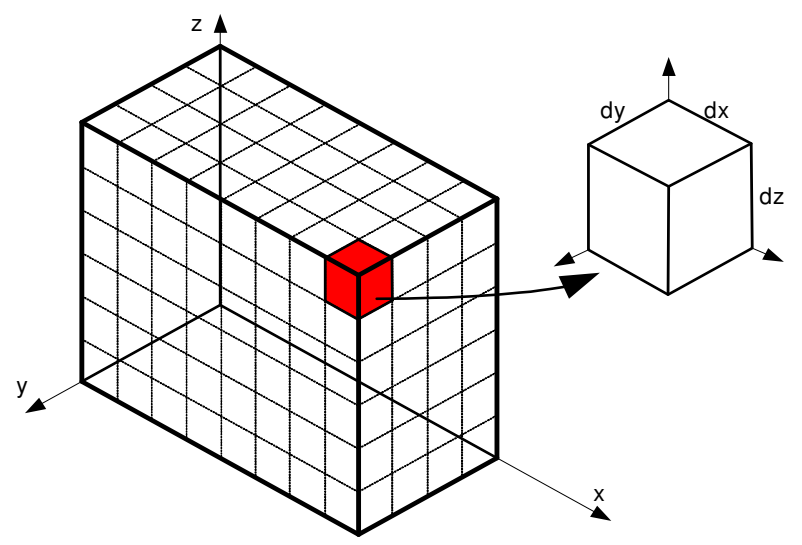

Fig. 8. Model heat exchanger and the recurrent fragment.

The analysed real cross-flow heat exchanger has been replaced with a model rectangular heat exchanger. The model was then divided into elementary fragments (Fig. 8). Each fragment represents a recurrent element of the real heat exchanger - a single tube with the rib (Piątek, 2003).

The energy balance equations for each fragment constitute the mathematical basis of the model. Assuming that the water flows along the $\mathrm{X}$ axis and the air flows along the $\mathrm{Y}$ axis the energy balance for a recurrent fragment may be written as follow:

$$
d \dot{Q}=-\dot{m}_{w} c_{p w} \frac{\partial T_{w}}{\partial x} d y d z=\dot{m}_{a} c_{p a} \frac{\partial T_{a}}{\partial y} d x d z=h_{a}\left(T_{m}-T_{a}\right) d A
$$

where $h_{a}$ is an average heat transfer coefficient on the gas side for all the ribbed surface and $\mathrm{T}_{\mathrm{m}}$ is the average temperature of rib and pipe surface.

The inlet temperatures of the mediums are known so the following boundary conditions may be used:

$$
T_{w}(0, y, z)=T_{w, i n} \quad T_{a}(x, 0, z)=T_{a, i n}
$$

The mass flow rates of the fluids are described by the following formulas:

$$
\begin{aligned}
& d \dot{m}_{w}=\frac{g_{w} \cdot \dot{m}_{w}}{Y_{\max } Z_{\max }} d y d z \\
& d \dot{m}_{a}=\frac{g_{a} \cdot \dot{m}_{a}}{X_{\max } Z_{\max }} d x d z
\end{aligned}
$$

The inequality factors $g_{w}$ and $g_{a}$ are defined as follows:

$$
g_{w}=\frac{w_{w}}{w_{w, m}}
$$




$$
g_{a}=\frac{w_{a}}{w_{a, m}}
$$

The subscript $\mathrm{m}$ in relationships (7) and (8) means the average velocity of the medium. Information about the non-uniform flow of the air is put into the model on the basis of measurements. A non-uniform water inlet to the exchanger may be set arbitral by a function or on the basis of numerical simulations (Bury et al., 2007a).

The control volume method based model of heat transfer for the recurrent fragment of the heat exchanger has been worked out to calculate the average temperature of the ribs and tube outer surface. The detailed description of the model and equations can be found in (Piątek, 2003).

The parameters calculated with the model of the recurrent fragment are: outlet and average temperature of the water flowing in the pipe, average temperature of the air, average temperature of the rib and the pipe surface, average values of the heat transfer coefficients at the gas side and the heat flux transported in the recurrent fragment. The heat transfer coefficient from the hot water to the pipe has been computed from Colburn's formula (Welty et al., 2008):

$$
N u=0.023 \cdot \operatorname{Re}^{0.8} \cdot \operatorname{Pr}^{1 / 3}
$$

The heat transfer coefficient on the gas side may be determined on the way of the numerical simulations for a numerical model of the recurrent fragment of the considered heat exchanger (see subsection 3.2.2 and Bury and Składzien, 2006) or may be computed from one of available Nusselt number correlations.

The calculation procedure for the whole exchanger model is iterative and it is repeated for all the recurrent fragments of the considered heat exchanger. First, the air temperature increase in the analysed fragment is assumed. Next, the heat transfer coefficients for the water and the gas sides are calculated as well as the rib and pipe surface average temperature. The heat flux transported in the recurrent fragment is then computed and the accuracy criterion is checked. If the criterion is satisfied the procedure is realized for the next fragment. If the criterion is not fulfilled the described procedure is then repeated for the given recurrent fragment till the demanded accuracy is achieved.

The validation procedure was performed by means of comparison of the experimental and numerical results. The total heat flux transported in the heat exchanger is the main compared parameter and it is the basis for evaluation of the code. Significant differences have been recorded between experimental and numerical data after the initial validation of the model (Bury et al., 2008a). Minor changes have been put into the code and the validation procedure was then repeated with usage of the infra-red thermography measurements results also. The last stage of the research was the sensitivity analysis (Bury et al., 2008b). This analysis has shown that the heat transfer coefficient from ribbed surfaces to the gas may be the reason for recorded discrepancies between numerical and experimental results.

\subsection{Heat transfer coefficient on the gas side}

\subsubsection{Application of Nusselt number correlations}

A traditional analysis of the convective heat transfer for simple cases is based on the similarity theory and application of the dimension analysis. It is very difficult to find an 
analytical solution for real cases and extensive measurements are necessary. A statistic analysis of the experimental results allows formulating an empirical correlation. A large number of such relationships have been worked so far. It should be however mentioned here that their application is limited to the heat exchangers of the same or very similar constructions to the experimental units. A review of available correlations allowed choosing those applicable for the heat exchangers under consideration. Six formulas have been investigated (Kays and London, 1998; Welty et al., 2008):

- $\quad$ Kays and London correlation:

$$
N u=\frac{0.011 \cdot \operatorname{Re}^{-0.418} \cdot \dot{m}_{a, \max } \cdot c_{p}}{\operatorname{Pr}^{2 / 3}}\left(\frac{D_{h}}{k_{a}}\right)
$$

- Berman correlation:

$$
N u=0.3375 \cdot \operatorname{Re}^{0.633}
$$

- $\quad$ Brigs and Young correlation:

$$
N u=0.134 \cdot \operatorname{Re}^{0.681} \cdot \operatorname{Pr}^{0.333}\left(\frac{s}{l}\right)^{0.2}\left(\frac{s}{\delta}\right)^{0.1131}
$$

- Norris and Spofford correlation:

$$
N u=1.0 \cdot \operatorname{Re}^{1 / 2} \cdot \operatorname{Pr}^{1 / 3}
$$

- Paikert correlation:

$$
N u=0.26 \cdot \operatorname{Re}^{0.6} \cdot \operatorname{Pr}^{0.333}\left(\frac{A_{0}}{A_{e}}\right)^{0.6}\left(\frac{A}{A_{G 0}}\right)^{-0.15}
$$

where

$$
\left(\frac{A_{0}}{A_{e}}\right)=\frac{s_{t p}(s+\delta)}{\left(s_{t p}-d\right) \cdot s+\left(s_{t p}-d-2 \cdot l\right) \cdot \delta},\left(\frac{A}{A_{G 0}}\right)=1+\frac{2 \cdot l \cdot(l+d+\delta)}{d \cdot(s+\delta)}
$$

- Schmidt correlation:

$$
N u=0.3 \cdot \operatorname{Re}^{0.625} \cdot \operatorname{Pr}^{0.333}\left(\frac{A_{r+p}}{A_{p}}\right)^{-0.375}
$$

The relationships shown above have been used to calculate the heat transfer coefficient for the air velocity ranging from 2 to $20 \mathrm{~m} / \mathrm{s}$ and for the air temperatures equal to $10^{\circ} \mathrm{C}, 20^{\circ} \mathrm{C}$ or $30^{\circ} \mathrm{C}$. The range of the air parameters has been established based on the experiments.

Figure 9 illustrates how big the discrepancy of the heat transfer coefficient is obtained depending on the choice of Nusselt number relationship. The use of different empirical correlations does not lead to conclusive results, but difficult to find criteria for selecting the 
correct equation for the present case (range of Reynolds numbers and the equivalent diameter of the pipes are not sufficient criteria). The Kays and London correlations (presented for the specific geometry of the heat exchanger core) seem to be the most accurately determined according to empirical findings. But it is hard to tell what the impact of differences in the geometric parameters of the heat exchangers cores used in the study is.

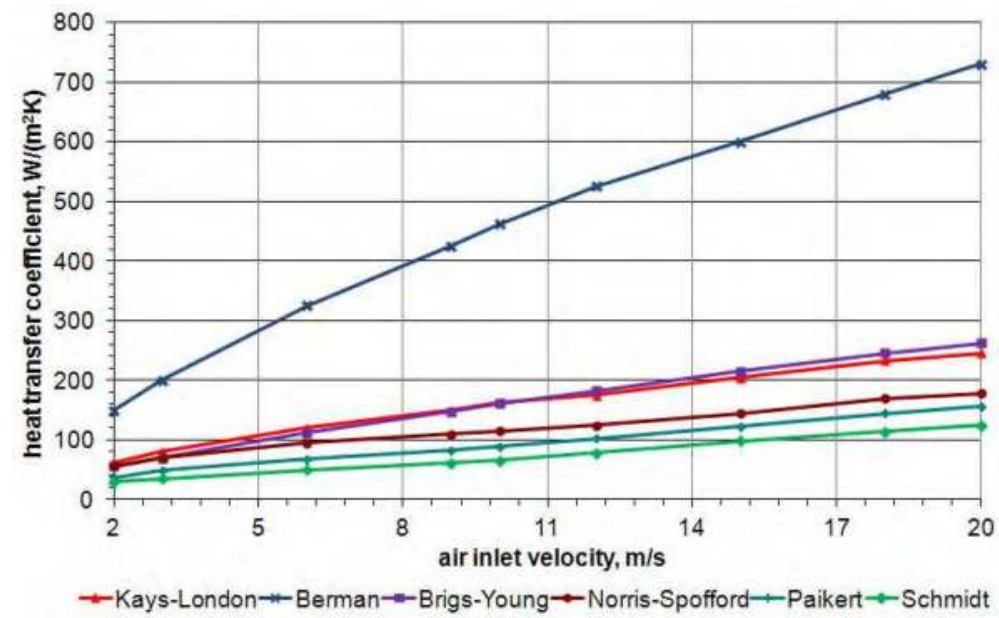

Fig. 9. Comparison of results obtained by different Nusselt number correlations for HE-1 heat exchanger.

\subsubsection{Numerical simulations using CFD software}

Two geometrical models have been made for numerical computations: the recurrent element of the considered heat exchangers and the recurrent segment - see Fig. 10. Geometries and numerical grids have been created using Gambit pre-processor.

The models of the recurrent segments of the radiators are related to the measurement series which results were described earlier. Each model consists of one or two rows of pipes and there are ten ribs in each row. The reason for the creation of these two numerical models is to test whether the simplification of real geometries affect the results.

The testing computations have shown that for considered models non-structured meshes are useless in most cases - the calculations were not converged or gave non-physical results. So for the fundamental computations for the recurrent element the structured meshes of 170 to 250 thousands cells for single recurrent element have been chosen.

The Reynolds Stress Model of turbulence has been chosen for the fundamental computations. The standard k- $\varepsilon$ and the realizable k- $\varepsilon$ models have been also tested, but some problems appeared during the calculations at low velocities of the air.

The Fluent CFD software has been applied for simulations. It has been assumed that the air inlet is parallel to the $X$ axis of the models. Except the inlet and the outlet surfaces all of the remaining planes have been assumed as the symmetry planes. First the testing computations have been performed to choose the proper numerical grid and the turbulence 
model. These computations have been realized for the air inlet temperatures of $10^{\circ} \mathrm{C}, 20^{\circ} \mathrm{C}$ or $30^{\circ} \mathrm{C}$, and the velocity ranging from $2 \mathrm{~m} / \mathrm{s}$ to $20 \mathrm{~m} / \mathrm{s}$. The water temperature has been assumed equal to $90^{\circ} \mathrm{C}$, and the heat transfer coefficient inside the pipes has been calculated from the Colburn relationship.
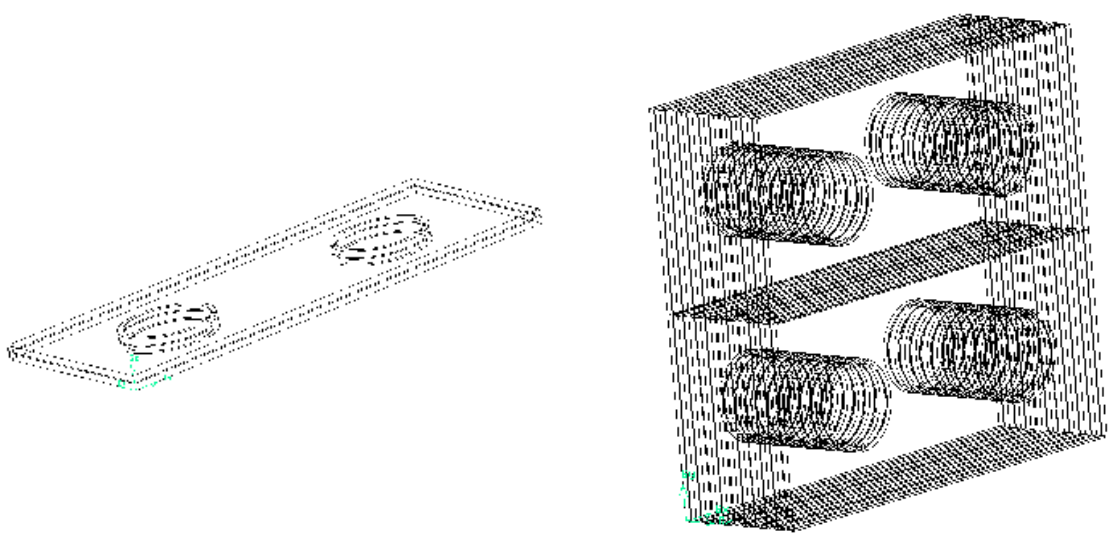

Fig. 10. The recurrent element (left) and the recurrent fragment (right) of the heat exchanger HE-1.

The averaged value of the heat transfer coefficient at the air side has been calculated based on the known fields of temperature for the rib surface and the pipe surface as well as the average temperature of the air and the transferred heat flux - see (Bury and Składzien, 2006) for details. The results for the HE-1 exchanger obtained by using the recurrent element model are presented in Fig. 11.

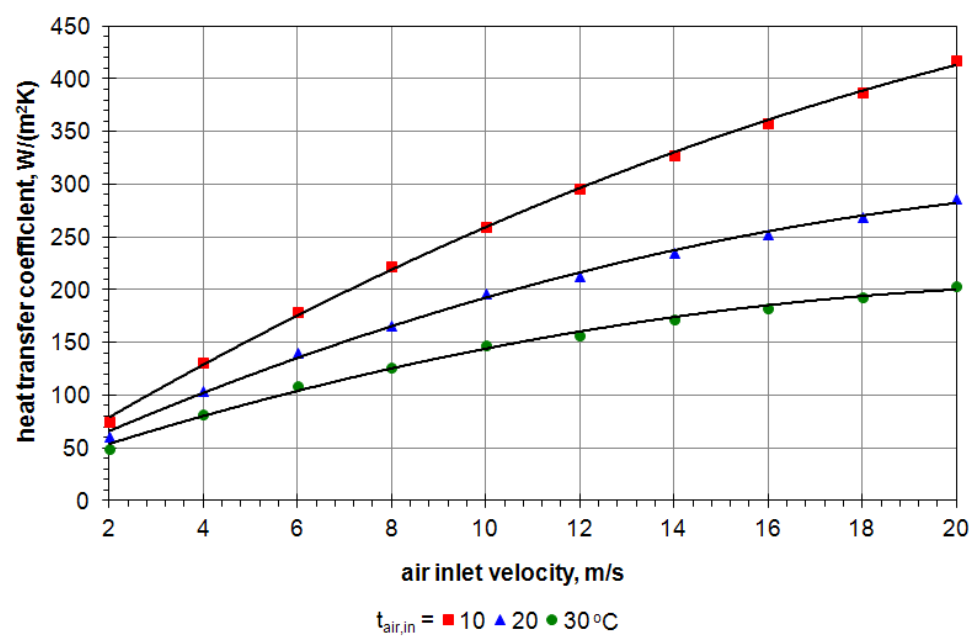

Fig. 11. Heat transfer coefficient versus the air inlet velocity - HE-1 exchanger, recurrent element model. 
The comparison of results for the recurrent element and recurrent segment is shown in Fig. 12. One may observe that the values of the air heat transfer coefficient obtained from the segment model are higher than the results from the element model. The initial difference reaches almost 22 per cent and it decreases down to 6 per cent along with the rising velocity of the air. The more significant difference for the lower velocities may be an effect of a nonfully developed turbulence. Using the recurrent fragment model allows for more accurate mapping of the real object, but also increases the computation time almost ten times.

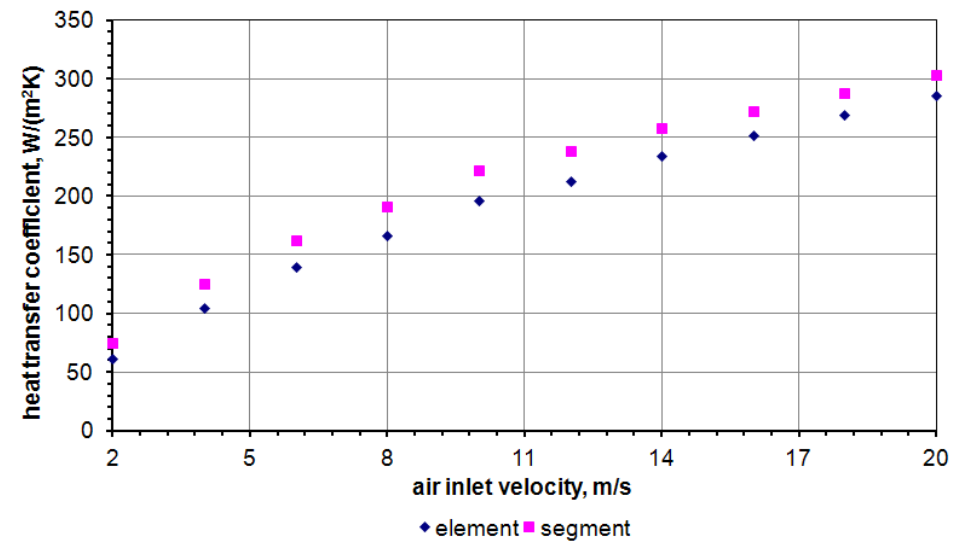

Fig. 12. Heat transfer coefficient versus the air inlet velocity - comparison of results for the recurrent element and segment of HE-1 exchanger.

\subsubsection{Validation of the numerical procedure for the heat transfer coefficient determination}

A simple comparison of heat transfer coefficient values presented in subsections 3.2.1 and 3.2.2 allows to see large differences, both between the empirical correlations and numerical models. Computational results, however, appear to coincide with the results obtained using the Kays-London correlations, which were previously considered to be the most accurate. Numerical approach is very convenient for the considered problem: it allows both to reproduce the accurate geometry of the recurrent element of the actual heat exchanger, as well as to take account of the non-uniform air flow. However, requires detailed plausibility study.

An enlarged special model of a fragment of the heat exchanger HE-1 has been built in order to check the numerical procedure responsible for determination of the heat transfer coefficient from the ribs to the gas.

The model consists of four plate ribs with respective pipe sections. Two electric heaters simulate the hot water flow inside the pipes. This model is placed in a flow channel with an observation window and it is cooled by the forced air flow (see Fig. 13). The air flow rate and temperatures at the inlet and outlet are measured. The infra-red thermography technique is used for measurement of the temperature field on the surface of the first rib. Several thermocouples are also installed for measuring the temperature on the other ribs surfaces. 


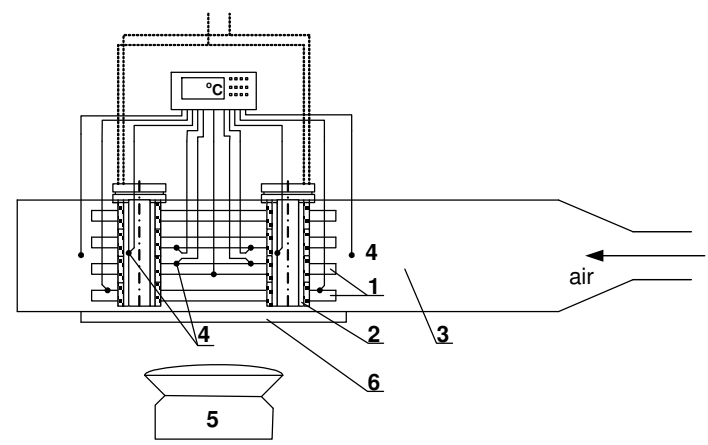

Fig. 13. Simplified sketch of the test station (1 - ribs and pipe models, 2 - electric heaters, 3 flow channel, 4 - thermocouples, 5 - infra-red camera, 6 - speculum).

Two parameters have been set as independent during experiments: the temperature of the pipe internal wall and the air flow rates. Following parameters have been recorded during measurements:

- the air volumetric flow rate,

- the air temperature at the inlet and outlet of the ribs section $t_{a, \text { in }}$ and $t_{a, \text { out, }}$

- electric power consumed by the heaters $\mathrm{N}_{\mathrm{h}}$

- the electric heater surface temperature $t_{h 1}$ and $t_{h 2}$ (assumed after as the pipe inner surface temperature),

- temperatures on the ribs surfaces in the measuring points (seven measuring points have been marked as L1, L2, L3, M, R1, R2 and R3),

- temperature distribution on the surface of the first rib.

There have been 25 measurements realized within the framework of this project. These experiments have been divided into five measuring series differing with the set temperature of the electric heaters (from 50 to 90 degrees Celsius with ten degree step). The range of the independent parameters changes has been chosen to obtain flow conditions (Reynolds' number) similar to those from the main testing station. Selected results of experiments are presented in Table 2. Sample temperature distribution measured during experiment MS-2 is presented in Fig. 14.

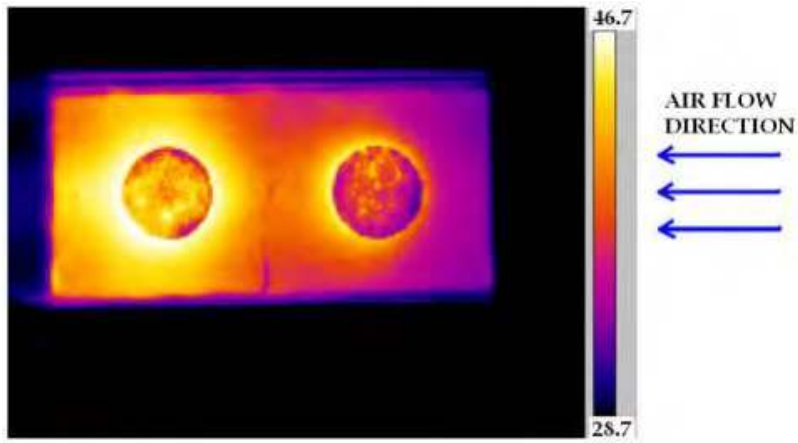

Fig. 14. Sample infrared thermographic picture of the first rib surface - experiment MS-2. 


\begin{tabular}{|c|c|c|c|c|c|c|c|c|c|c|c|c|c|}
\hline \multirow{2}{*}{$\begin{array}{c}\text { Meas. } \\
\text { No. }\end{array}$} & $\dot{\mathrm{V}}_{\mathrm{a}}$ & $\mathrm{t}_{\mathrm{h} 1}$ & $\mathrm{t}_{\mathrm{h} 2}$ & $\mathrm{~N}_{\mathrm{h}}$ & $\mathrm{t}_{\mathrm{a}, \mathrm{in}}$ & $\mathrm{t}_{\mathrm{a}, \text { out }}$ & $\mathrm{t}_{\mathrm{L} 1}$ & $\mathrm{t}_{\mathrm{L} 2}$ & $\mathrm{t}_{\mathrm{L} 3}$ & $\mathrm{t}_{\mathrm{M}}$ & $\mathrm{t}_{\mathrm{R} 1}$ & $\mathrm{t}_{\mathrm{R} 2}$ & $\mathrm{t}_{\mathrm{R} 3}$ \\
\hline & $\mathrm{m}^{3} / \mathrm{s}$ & ${ }^{\circ} \mathrm{C}$ & ${ }^{\circ} \mathrm{C}$ & $\mathrm{W}$ & ${ }^{\circ} \mathrm{C}$ & ${ }^{\circ} \mathrm{C}$ & ${ }^{\circ} \mathrm{C}$ & ${ }^{\circ} \mathrm{C}$ & ${ }^{\circ} \mathrm{C}$ & ${ }^{\circ} \mathrm{C}$ & ${ }^{\circ} \mathrm{C}$ & ${ }^{\circ} \mathrm{C}$ & ${ }^{\circ} \mathrm{C}$ \\
\hline MS-1 & $7.03 \cdot 10^{-3}$ & 49.5 & 50.2 & 116.5 & 24.0 & 37.5 & 45.3 & 40.0 & 49.4 & 42.3 & 37.3 & 38.0 & 37.9 \\
\hline MS-5 & $12.47 \cdot 10^{-3}$ & 49.7 & 50.4 & 137.1 & 22.9 & 31.1 & 38.6 & 33.8 & 43.2 & 38.9 & 31.2 & 31.4 & 31.6 \\
\hline MS-6 & $7.00 \cdot 10^{-3}$ & 59.6 & 60.5 & 143.3 & 24.1 & 40.1 & 46.0 & 41.9 & 53.6 & 46.5 & 39.2 & 38.3 & 37.8 \\
\hline MS-10 & $12.47 \cdot 10^{-3}$ & 60.1 & 60.7 & 152.5 & 23.4 & 33.1 & 41.7 & 35.9 & 43.7 & 40.9 & 33.1 & 31.0 & 31.8 \\
\hline MS-11 & $7.03 \cdot 10^{-3}$ & 69.6 & 70.7 & 159.6 & 24.2 & 41.9 & 50.1 & 46.3 & 55.2 & 48.7 & 38.2 & 38.2 & 42.3 \\
\hline MS-15 & $12.47 \cdot 10^{-3}$ & 69.9 & 71.1 & 173.4 & 23.7 & 34.4 & 42.9 & 40.3 & 45.3 & 43.1 & 36.9 & 33.8 & 34.5 \\
\hline MS-16 & $7.00 \cdot 10^{-3}$ & 79.5 & 80.6 & 179.1 & 24.0 & 44.5 & 52.0 & 45.6 & 56.8 & 48.5 & 41.9 & 41.2 & 42.2 \\
\hline MS-20 & $12.50 \cdot 10^{-3}$ & 79.2 & 80.0 & 189.2 & 24.2 & 36.2 & 45.3 & 39.4 & 47.7 & 45.1 & 35.8 & 33.9 & 36.2 \\
\hline MS-21 & $7.03 \cdot 10^{-3}$ & 93,7 & 90.4 & 192.0 & 23.9 & 44.8 & 56.1 & 48.3 & 60.1 & 52.4 & 41.8 & 39.7 & 42.1 \\
\hline MS-25 & $12.53 \cdot 10^{-3}$ & 89.7 & 90.6 & 215.8 & 24.5 & 38.3 & 46.5 & 39.1 & 48.3 & 42.4 & 35.2 & 32.8 & 35.3 \\
\hline
\end{tabular}

Table 2. Selected results of measurements.

All experiments described above have been next simulated using numerical model of the laboratory stand. The same assumptions as used during creation of the models described in subsection 3.2.2 have been applied. The numerical model of the system under consideration is a part of the laboratory stand and contains the flow channel with the ribs section. The geometry of the model has been created using Gambit preprocessor and it is shown in Fig. 15 as well as the boundary conditions types. All remaining boundary conditions have been set as coupled and isolated walls for external surfaces of the model. The numerical model contains near 560 thousands of tetrahedral cells.

All performed simulations have been realized using the measured air flow rate and the electric heaters surfaces temperature as the boundary conditions. A part of simulations also considered thermal radiation. The surface to surface model of this phenomena implemented into the Fluent has been applied.

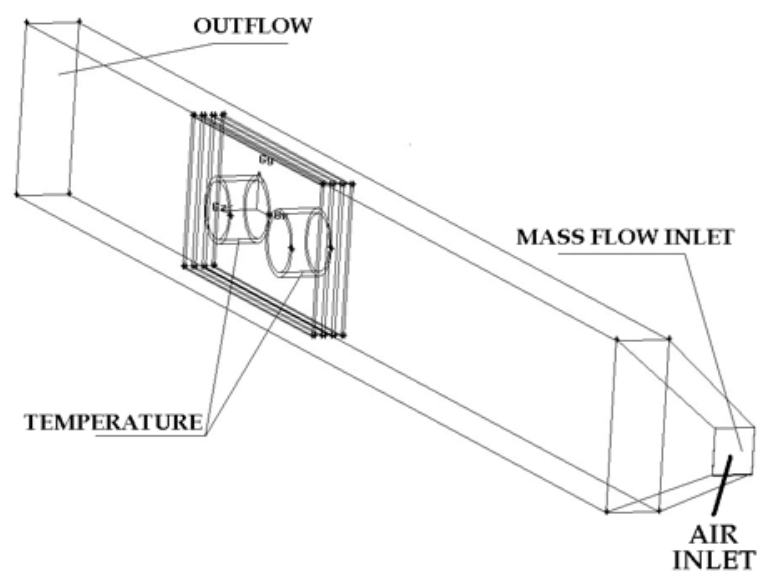

Fig. 15. Geometry of the numerical model of the test rig and boundary conditions types. 
Selected results of simulations of the MS-1 experiment are presented in Fig. 16. The CFD analysis gives the possibility to view fields of the most important parameters in different cross sections of the object under consideration. The air velocity distribution is shown in Fig. 16 on left. The cross section plane is parallel to the flow direction and it crosses the second rib. One may note that the air inflow to the ribs section is quite well unified.

The most interesting numerical results are the temperature distributions on the first rib surface (see Fig. 16 on right), as well as the experimental results. These distributions may be next compared with the infra-red thermography measurements.

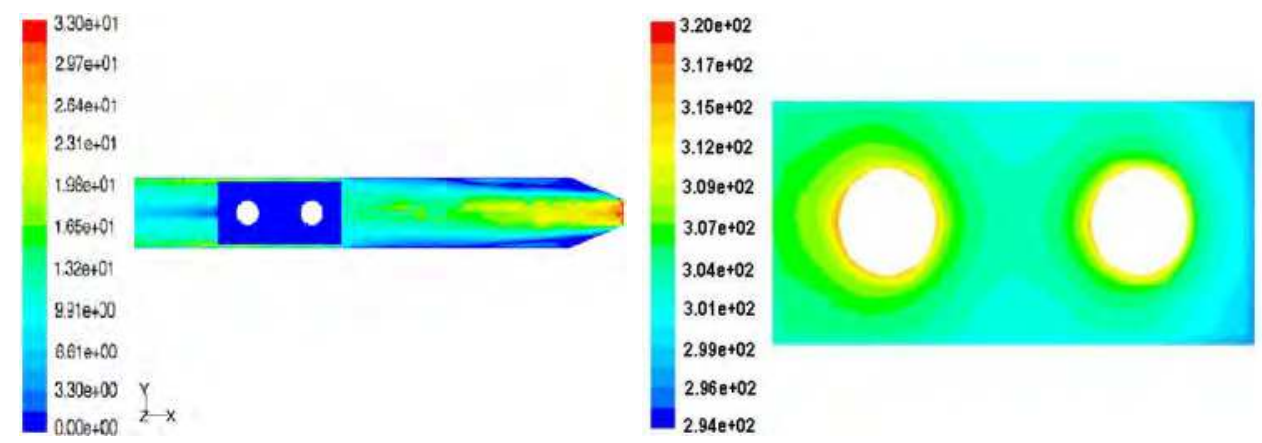

Fig. 16. The air velocity contours (left $-\mathrm{m} / \mathrm{s}$ ) and temperature distribution on the first rib surface (right - K) for the MS-1 experiment.

The main goal of the analysis is to evaluate the numerical CFD model used for computations of the heat transfer coefficient at the gas side of the considered heat exchanger. A simple comparison of measured and computed temperatures for two analyzed experiments is presented in Table 3. The first three thermocouples are placed on the first rib visible surface and are also used for calibration of the infra-red camera. The calculated surface temperature values are a little bit underestimated, as well as the air outlet temperature. The last parameter is computed as the area weighted average value for the cross section placed $2 \mathrm{~cm}$ next to the ribs section.

The most interesting is comparison of the temperature field for the first rib surface (see Fig. 17). Due to different color scales a direct comparison is somewhat difficult but one can see that similarity of temperature distributions is quite good, both quantitatively and qualitatively.

\begin{tabular}{|c|c|c|c|c|c|c|c|c|c|}
\cline { 3 - 10 } \multicolumn{2}{c|}{} & $\mathrm{t}_{\mathrm{L} 1},{ }^{\circ} \mathrm{C}$ & $\mathrm{t}_{\mathrm{L} 2,}{ }^{\circ} \mathrm{C}$ & $\mathrm{t}_{\mathrm{L} 3},{ }^{\circ} \mathrm{C}$ & $\mathrm{t}_{\mathrm{M}},{ }^{\circ} \mathrm{C}$ & $\mathrm{t}_{\mathrm{R} 1},{ }^{\circ} \mathrm{C}$ & $\mathrm{t}_{\mathrm{R} 2},{ }^{\circ} \mathrm{C}$ & $\mathrm{t}_{\mathrm{R} 3},{ }^{\circ} \mathrm{C}$ & $\mathrm{t}_{\mathrm{a}, \text { out }},{ }^{\circ} \mathrm{C}$ \\
\hline \multirow{2}{*}{ MS-4 } & Measurement & 40.4 & 41.5 & 34.5 & 43.9 & 39.8 & 40.6 & 33.9 & 33.4 \\
\cline { 2 - 10 } & Simulation & 40.1 & 40.9 & 33.8 & 43.5 & 39.4 & 39.9 & 33.3 & 32.9 \\
\hline \multirow{2}{*}{ MS-22 } & Measurement & 56.2 & 57.7 & 48.0 & 61.1 & 55.4 & 56.5 & 47.2 & 42.9 \\
\cline { 2 - 11 } & Simulation & 55.5 & 56.2 & 47.1 & 60.5 & 54.6 & 55.1 & 46.3 & 41.3 \\
\hline
\end{tabular}

Table 3. Comparison of experimental and numerical data for the rib temperature - sample results. 

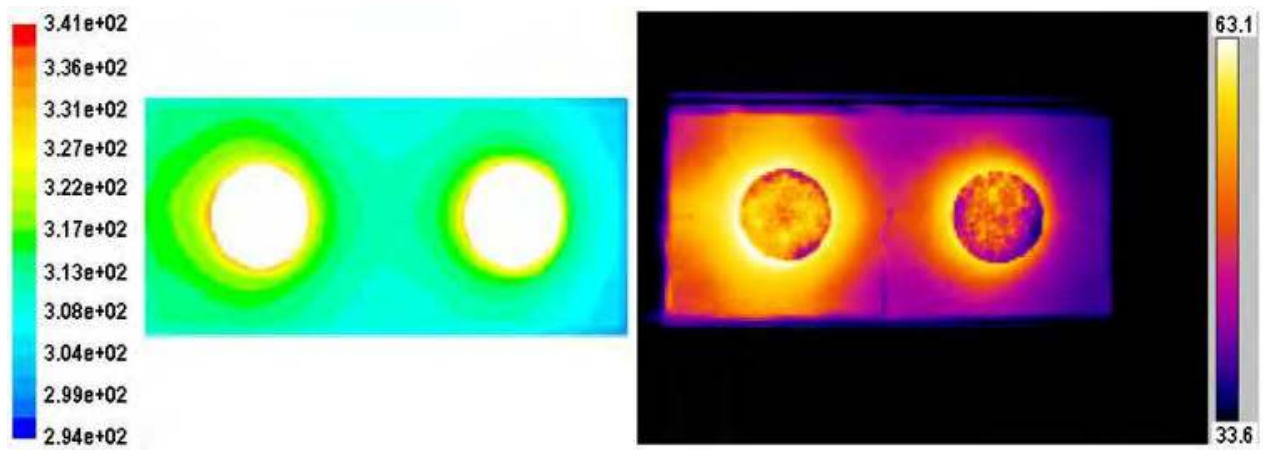

Fig. 17. Calculated (left, $\mathrm{K}$ ) and measured (right, ${ }^{\circ} \mathrm{C}$ ) temperature field of the first rib surface for experiment MS-4 - air flow direction same as in Fig. 14.

The next step in the analysis was the computation and comparison of the total heat flow rates transported from the ribbed surface to the flowing air. The results for measuring series MS-1 to MS-5 and MS-21 to MS-25 are presented in Table 4. The total heat flow rates has been calculated twice based on the air enthalpy rise:

- considering the measured values of the volumetric air flow and its temperature measured at the inlet and outlet of the ribs section $(\dot{Q}$ air in Table 4$)$,

- taking into account the computed values of the mentioned parameters ( $\dot{Q}_{\text {Fluent }}$ in Table 4).

\begin{tabular}{|l|c|c|c|c|c|}
\hline Measurement No. & $\mathrm{N}_{\mathrm{h}} \mathrm{W}$ & $\dot{Q}_{\text {air }}, \mathrm{W}$ & $\dot{Q}_{\text {Fluent, }} \mathrm{W}$ & $\delta \dot{Q}_{\text {air }} \%$ & $\delta \dot{Q}_{\text {Fluent, } \%}$ \\
\hline MS-1 & 116.5 & 111.8 & 104.5 & 4.03 & 10.30 \\
\hline MS-2 & 122.6 & 117.2 & 109.9 & 4.40 & 10.36 \\
\hline MS-3 & 128.0 & 119.0 & 111.7 & 7.03 & 12.73 \\
\hline MS-4 & 132.4 & 117.2 & 109.9 & 11.48 & 16.99 \\
\hline MS-5 & 137.1 & 120.9 & 113.6 & 11.82 & 17.14 \\
\hline MS-21 & 192.0 & 173.1 & 165.8 & 9.84 & 13.65 \\
\hline MS-22 & 196.5 & 186.2 & 178.9 & 5.24 & 8.96 \\
\hline MS-23 & 200.5 & 190.7 & 183.4 & 4.89 & 8.53 \\
\hline MS-24 & 207.0 & 200.0 & 192.7 & 3.38 & 6.91 \\
\hline MS-25 & 215.8 & 203.3 & 196.0 & 5.79 & 9.18 \\
\hline
\end{tabular}

Table 4. Comparison of experimental and computational data - heat flow rates.

The relative differences $(\delta \dot{Q})$ between experimental and numerical results have been calculated. The heat flow rates calculated based on the measured values, as it can be seen, is lower than the measured values of the electric power of the heaters. The obvious reason of this situation is the heat losses through the rear wall of the flow channel. The differences between experimental and computational heat flow rates calculated as the CFD results reach up to $18 \%$ for some cases, but the average difference is somewhat over $10 \%$. 
In the paper (Bury et al., 2009a) authors concluded that neglecting of thermal radiation phenomena may be a reason of discrepancies between numerical and experimental results. An additional set of simulations has been initiated taking into account thermal radiation. The results however have shown almost no differences in comparison to these shown in Table 4. This situation could be an effect of assuming dry air flow through the ribs section. This gas contains mostly two-atom particles and it is almost optically inactive regarding the thermal radiation.

According to the results of analyses it may be noted that the CFD based numerical model portrays the physical phenomena with satisfying accuracy. Probable reasons of recorded discrepancies are some simplifications in the numerical model geometry as well as neglecting the heat losses to the environment.

\subsection{Results of numerical simulations}

The analyses presented in subsection 3.2 allowed to withdrawn following conclusions:

- application of available correlations for Nusselt number leads to a wide deviation of the heat transfer coefficient values; it is difficult to define the characteristic dimension in some cases; even application of Kays-London approach (assumed as the most accurate) does not assure reliable results,

- the numerical models of recurrent element and recurrent segment of considered heat exchangers give the heat transfer coefficient results within the range determined by investigated correlations for Nusselt number; the results obtained by using the recurrent element and recurrent segment differ, especially at low velocities; application of the recurrent segment model seems to be more correct but it needs a lot of computing time; such approach allows for detailed representation of real geometries in numerical model.

\begin{tabular}{|c|c|c|c|}
\hline Measurement No. & $\dot{Q}_{\text {num, }} \mathrm{kW}$ & $\dot{Q}_{\text {ex }}, \mathrm{kW}$ & $\delta \dot{Q}, \%$ \\
\hline HE-1/1 & 12.78 & 11.03 & 15.9 \\
\hline HE-1/2 & 26.44 & 22.61 & 16.9 \\
\hline HE-1/3 & 39.96 & 34.08 & 17.3 \\
\hline HE-1/4 & 11.11 & 9.72 & 14.3 \\
\hline HE-1/5 & 22.44 & 19.42 & 15.6 \\
\hline HE-1/6 & 33.48 & 29.11 & 15.0 \\
\hline HE-2/1 & 11.59 & 10.07 & 15.1 \\
\hline HE-2/2 & 16.24 & 14.08 & 15.4 \\
\hline HE-2/3 & 22.75 & 19.58 & 16.2 \\
\hline HE-2/4 & 5.10 & 4.48 & 13.9 \\
\hline HE-2/5 & 13.76 & 12.04 & 14.3 \\
\hline HE-2/6 & 22.68 & 19.76 & 14.8 \\
\hline HE-3/1 & 14.27 & 12.39 & 15.2 \\
\hline HE-3/2 & 20.02 & 17.31 & 15.6 \\
\hline HE-3/3 & 28.10 & 24.08 & 16.7 \\
\hline HE-3/4 & 6.28 & 5.51 & 14.0 \\
\hline HE-3/5 & 17.00 & 14.81 & 14.8 \\
\hline HE-3/6 & 28.14 & 24.30 & 15.8 \\
\hline
\end{tabular}

Table 5. Selected computational results. 
Considering the abomentioned facts it was decided to apply the CFD approach with the recurrent elements models for determination of the heat transfer coefficient from ribbed surfaces to the flowing air during the numerical simulations.

Simulations were aimed in determination of the non-uniform air inlet impact on the heat exchangers efficiency and have been realized using the described earlier model and the computer code HEWES. All these simulation have been performed applying the uniform air inflow to the exchanger. The uniform mass flow rate of the air has been derived assuming that the total mass flow rate of the air spreads equally on the all measuring fields. The selected results of computations are gathered in Table 5 and, as expected, they shown quite significant improvement of the efficiency of the heat exchanger. The efficiency growth raises with increasing the air flow rate and water inlet temperature.

The numbers in the last column of Table 5 give an average value of $15 \%$. This should be considered as significant deterioration of the cross-flow heat exchanger thermal efficiency due to the medium flow maldistribution. Moreover, these results obtained for three units with different ribbing structure are similar. So, it seems that the air inlet non-uniformity affects the performance of the heat exchangers under consideration to the same extent.

\section{Conclusions}

The experiments performed for three considered cross-flow heat exchangers have shown that the air inflow non-uniformity range may be significant and its form depends on the air volumetric flow rate in the considered configuration. The experimental data allowed for determination of the total heat flow rates transported between the agents in the heat exchangers.

The computational results, as it was expected, have shown significant decrease in the heat flow rates comparing with the exchanger with fully uniform air inflow. The average deterioration factor is about $15 \%$. Two aspects should be taken into account while evaluating the numbers from Table 5: the measurements errors and the accuracy of the code HEWES. Taking into account accuracy of the measuring instruments the maximum measurements error has been determined to be of $\pm 4 \%$. The uncertainty of numerical results has been assessed during the validation of the code - see (Bury et al., 2008a; Bury et al., $2008 \mathrm{~b}$ ) for more details - and the differences between numerical and experimental results may reach almost $11 \%$. These two numbers and the fact that the numerical results are always underestimated allow to conclude that the air inlet maldistribution has significant impact on a cross-flow heat exchanger performance.

Following final conclusions and remarks can be pointed for summarizing this study:

- experimental and numerical analyses accomplished within the framework of investigations confirmed the earlier observations about significant meaning of media flow maldistribution for cross-flow heat exchanger thermal performance,

- results concerning the increase of the efficiency due to uniformization of flow obtained in this work remain in the range achieved by the other researchers,

- application of CFD tools for computational analyses of heat exchangers may be useful and reliable but models should be thoroughly validated first; further validation of the numerical models described in subsection 3.2.2 is planned in the nearest future for models of ribs referring to HE- 2 and HE- 3 heat exchangers. 
The author realizes that the combination of experimental tests and numerical simulations to assess the impact of inequality for the work of the heat exchangers may be the subject of some criticism. The best solution would be to do all the analysis by means of measurements. However, to obtain a homogeneous air flow on the described testing rig, while maintaining the appropriate parameters, it is impossible due to technical limitations. Some attempts to implement this idea has been taken in (Bury et al., 2009b), and although it failed to get the full homogeneity of the flow, it was noted the positive effects.

\section{Acknowledgment}

This investigation was supported by the Polish Ministry of Science and Higher Education under the project No. N N512 458836. Technical support of the GEA Heat Exchangers Company is also acknowledged.

\section{Nomenclature}

\begin{tabular}{|c|c|c|c|}
\hline$c_{p}$ & - specific heat capacity at constant & $\dot{Q}$ & - heat flow rate, $\mathrm{W}$ \\
\hline & pressure, J/(kg K) & $\operatorname{Re}$ & - Reynolds number \\
\hline $\mathrm{d}$ & - heat exchanger pipe diameter, $\mathrm{m}$ & $\mathrm{s}$ & - distance between ribs, $\mathrm{m}$ \\
\hline $\mathrm{D}_{\mathrm{h}}$ & - hydraulic diameter, $\mathrm{m}$ & $S$ & - $\quad$ surface area, $\mathrm{m}^{2}$ \\
\hline $\mathrm{h}$ & - heat transfer coefficient, $\mathrm{W} /\left(\mathrm{m}^{2} \mathrm{~K}\right)$ & $S_{\text {tp }}$ & - transverse distance between \\
\hline $\mathrm{k}$ & - thermal conductivity, $\mathrm{W} /(\mathrm{m} \mathrm{K})$ & & pipes, $\mathrm{m}$ \\
\hline 1 & - height of a rib, $\mathrm{m}$ & $\mathrm{t}, \mathrm{T}$ & - temperature, ${ }^{\circ} \mathrm{C}, \mathrm{K}$ \\
\hline$\dot{m}$ & - mass flow rate, $\mathrm{kg} / \mathrm{s}$ & $\dot{V}$ & - volumetric flow rate, $\mathrm{m}^{3} / \mathrm{s}$ \\
\hline $\mathrm{Nu}$ & - Nusselt number & $\delta$ & - thickness of a rib, $\mathrm{m}$ \\
\hline $\operatorname{Pr}$ & - Prandtl number & $\rho$ & - mass density, $\mathrm{kg} / \mathrm{m}^{3}$ \\
\hline
\end{tabular}

Subscripts

$\begin{array}{llll}\text { a } & \text { - air } & \mathrm{p} & - \text { refer to pipes without ribs } \\ \text { in } & - \text { inlet } & \mathrm{r} & - \text { refer to ribbed surface } \\ \max & - \text { maximum value } & \mathrm{w} & - \text { water } \\ \text { out } & \text { - outlet } & & \end{array}$

\section{References}

Aganda, A.A.; Coney, J.E.R.; Farrant, P.E.; Sheppard, C.G.W. \& Wongwuttanasatian, T. (2000). A Comparison of the Predicted and Experimental Heat Transfer Performance of a Finned Tube Evaporator. Applied Thermal Engineering, Vol. 20, No. 6, (June 2000), pp. 499-513, ISSN 1359-4311

Andrecovich, M. \& Clarke, R. (2003). Simple Modeling of Flow Maldistribution in Plate-Fin Exchangers, Proceedings of the 21st IIR International Congress of Refrigeration, Paper ICR0639, Washington DC, USA, August 17-22, 2003

Anjun, J.; Rui, Z. \& Sangkwon J. (2003). Experimental Investigation of Header Configuration on Flow Maldistribution in Plate-Fin Heat Exchanger. Applied Thermal Engineering, Vol. 23, No. 10, (July 2003), pp. 1235-1246, ISSN 1359-4311

Berryman, R.J. \& Russell, C.M.B. (1987). The Effect of Maldistribution of Air Flow on Aircooled Heat Exchanger Performance, In: Maldistribution of Flow and Its Effect on 
Heat Exchanger Performance, J.B. Kitto \& J.M. Robertson (Eds.), pp. 19-23., ASME Htd, Vol. 75, ISBN 978-9991621319 (June 1987)

Bury, T. \& Składzien, J., (2006). The Experimental and the Numerical Analysis of a Ribbed Heat Exchanger With an Unequal Inlet of the Air, Proceedings of the 11th International Symposium on Heat Transfer and Renewable Sources of Energy, pp. 419426, Międzyzdroje, Poland, September 13-16, 2006

Bury, T.; Składzień, J. \& Piątek, R. (2007a). Experimental and Numerical Hydraulic Analysis of the Water Chiller With Unequal Inlet of the Agents, Proceedings of the 13th Symposium of Heat and Mass Transfer, pp. 297-304, Darłówko, Poland, September 3-6, 2007

Bury, T., Kruczek, T. \& Składzień, J. (2007b). Experimental Investigations of the Effectiveness of Functioning of the Cross-Flow Water Cooler With Unequal Flow of the Agents, Proceedings of the 1st Conference on Contemporary Power Engineering Technology, pp. 23-34, Kraków, Poland

Bury, T.; Piątek, R. \& Składzień, J. (2008a). Experimental Validation of The Numerical Thermal Model Of The Cross-Flow Heat Exchanger With Unequal Agent Flow. Proceedings of the 21st International Conference on Efficiency, Cost, Optimization, Simulation and Environmental Impact of Energy Systems - ECOS 2008, pp. 329-336, Kraków - Gliwice, Poland, June 24-27, 2008

Bury, T.; Składzien, J. \& Piątek, R. (2008b). Validation and Sensitivity Analysis of the Mathematical Model of a Cross-Flow Heat Exchanger with Non-Uniform Flow of Agents. Systems - Journal of Transdisciplinary Systems Science, Vol. 13, special issue 1/2, (November 2008), pp. , ISSN 1427-275X

Bury, T.; Składzień J. \& Sachajdak, A. (2009a). Experimental Validation of the Numerical Model of the Heat Transfer Coefficient Calculation for a Cross Flow Heat Exchangers. Proceedings of the 7th World Conference on Experimental Heat Transfer, Fluid Mechanics and Thermodynamics, on CD, Kraków, Poland, June 28 - July 3, 2009

Bury, T.; Składzień, J. \& Hanuszkiewicz-Drapała, M. (2009b). Experimental and Numerical Analyses of a Non-Uniform Agents Flow Impact on a Finned Cross-Flow Heat Exchanger Effectiveness. Proceedings of the 22nd International Conference on Efficiency, Cost, Optimization, Simulation and Environmental Impact of Energy Systems - ECOS 2009, on CD, Foz do Iguacu, Parana, Brasil, August 31 - September 3, 2009

Bury, T. \& Składzień, J. (2010). Verification of the CFD Model of the Heat Transfer Model on a Rib Surface. Proceedings of the 13th International Symposium on Heat Transfer and Renewable Sources of Energy, pp. 285-292, Szczecin - Międzyzdroje, Poland, September 9-12, 2010

Chwalowski, M.; Didion, D.A. \& Domanski, P.A. (1989). Verification of Evaporator Computer Models and Analysis of Performance of an Evaporator Coil. ASHRAE Transactions, Vol. 95, No. 2, (1989), pp. 1229-1236, ISSN 0001-2505

Fagan, T.J. (1980). The Effects of Air Flow Maldistributions on Air-to-Refrigerant Heat Exchanger Performance. ASHRAE Transactions, Vol. 86, No. 2, (1980), pp. 699-713, ISSN 0001-2505

Hanuszkiewicz-Drapała, M. (1996). Thermodynamic Analysis of a Cross-Flow Heat Exchanger with Non-uniform Flow of Agents, PhD Thesis, Institute of Thermal Technology, Silesian University of Technology, Gliwice, Poland (in Polish) 
Hoffmann-Vocke, J.; Neale, J. \& Walmsley, M. (2009). Flow Profiles on the Fin Side of a Plate Fin-And-Tube Heat Exchanger Experiencing Gross Flow Maldistribution, Proceedings of 7th World Conference on Experimental Heat Transfer, Fluid Mechanics and Thermodynamics, on CD, Kraków, Poland, June 28 - July 3, 2009

Hoffmann-Vocke, J.; Neale, J. \& Walmsley, M. (2011). The Effect of Inlet Conditions on the Air Side Hydraulic Resistance and Flow Maldistribution in Industrial Air Heaters. International Journal of Heat and Fluid Flow, Vol. 32, No. 4, (August 2011), pp. 834845, ISSN 0142-727X.

Kays; W.M. \& London, A.L. (1998). Compact Heat Exchangers, 3rd Revised Edition, Krieger Publishing Company, EAN 9781575240602, Malabar, Florida, USA

Lalot, S.; Florent, P.; Lang, S.K. \& Bergles, A.E. (1999). Flow Maldistribution in Heat Exchangers. Applied Thermal Engineering, Vol. 19, No. 8, (August 1999), pp. 847-863, ISSN 1359-4311

Lee, J. \& Domanski, P.A. (1997). Impact of Air and Refrigerant Maldistributions on the Performance of Finned-Tube Evaporators With R-22 and R-407C, Final Report, ARTI MCLR Project Number 665-54500, (July 1997), Arlington, USA

Lee, K.-S. \& Oh S.-J. (2004). Optimal Shape of the Multi-Passage Branching System in a Single-Phase Parallel-Flow Heat Exchanger. International Journal of Refrigeration, Vol. 27, No. 1, (January 2004), pp. 82-88, ISSN 0140-7007

Luo, X.; Roetzel, W. \& Lüdersen, U. (2001). The Single-Blow Transient Technique Considering Longtitudinal Core Conduction and Fluid Dispersion. International Journal of Heat and Mass Transfer, Vol. 44, No. 1, (January 2001), pp. 121-129, ISSN 0017-9310

Malinowski, Ł. (2008). Experimental and Numerical Analysis of a Non-Uniform Air Inflow to a Cross-Flow Heat Exchanger. MSc Thesis, Institute of Thermal Technology, Silesian University of Technology, Gliwice, Poland (in Polish)

Meyer, C.J. \& Kröger, D.G. (1998). Plenum Chamber Flow Losses in Forced Draught AirCooled Heat Exchangers. Applied Thermal Engineering, Vol. 18, No. 9-10, (September 1998), pp. 875-893, ISSN 1359-4311

Mueller, A.C. (1987). Effects of Some Types of Maldistribution on the Performance of Heat Exchanger. Heat Transfer Engineering, Vol. 8, No. 2, (1987), pp. 75-86, ISSN 0145-7632

Nair, S.; Verma, S. \& Dhingra, S.C. (1998). Rotary Heat Exchanger Performance With Axial Heat Dispersion. International Journal of Heat and Mass Transfer, Vol. 41, No. 18, (September 1998), pp. 2857-2864, ISSN 0017-9310

Piątek, R. (2003). Thermal Analysis of Plate Fin and Tube Heat Exchanger With Unequal Inlet of Media, PhD Thesis, Institute of Thermal Technology, Sielsian University of Technology, Gliwice, Poland (in Polish)

Ranganayakulu, Ch.; Seetharamu, K.N. \& Sreevatsan, K.V. (1996). The Effects of Inlet Fluid Flow Nonuniformity on Thermal Performance and Pressure Drops in Crossflow Plate-Fin Compact Heat Exchangers. International Journal of Heat and Mass Transfer, Vol. 40, No. 1, (October 1996), pp. 27-38, ISSN 0017-9310

Rao, B. P.; Sunden, B. \& Das S. K. (2006). An Experimental Investigation of the Port Flow Maldistribution in Small and Large Plate Package Heat Exchangers. Applied Thermal Engineering, Vol. 26, No. 16, (November 2006), pp. 1919-1926, ISSN 1359-4311

Shaji, K. \& Das S. K. (2010). The Effect of Flow Maldistribution on the Evaluation of Axial Dispersion and Thermal Performance During the Single-Blow Testing of Plate Heat 
Exchangers. International Journal of Heat and Mass Transfer, Vol. 53, No. 7-8, (March 2010), pp. 1591-1602, ISSN 0017-9310

Składzień, J. \& Bury T. (2011). Application of Infra-Red Thermography for Validation of the Heat Transport Model on a Rib Surface. Proceedings of the 6th International Conference on Transport Phenomena in Multiphase Systems, pp. , Ryn, Poland, June 28 - July 2, 2011

Srihari, N. \& Das S. K. (2008). Transient Response of Multi-Pass Plate Heat Exchangers Considering the Effect of Flow Maldistribution. Chemical Engineering and Processing: Process Intensification, Vol. 47, No. 4, (April 2008), pp. 695-707, ISSN 0255-2701

Srihari, N.; Rao, B.P.; Sunden, B. \& Das S. K. (2005). Transient Response of Plate Heat Exchangers Considering Effect of Flow Maldistribution. International Journal of Heat and Mass Transfer, Vol. 48, No. 15, (July 2005), pp. 3231-3243, ISSN 0017-9310

Taler, D. \& Cebula, A. (2004). Numerical Modeling of the Heat Transfer in the Lamel Type Heat Exchangers, Proceedings of the 12th Symposium on Heat and Mass Transfer, Vol. 2, pp. 827-836, Kraków, Poland, June 15-18, 2004

Taler, D. (2002). Theoretical and Experimental Analysis of Heat Exchangers With Extended Surfaces. Polish Academy of Sciences, Papers of the Scientific Commission of Automotive Industry, Vol. 25, No. 3, Kraków, Poland

Welty, J.; Wicks, C.E.; Rorrer, G.L. \& Wilson, R.E. (2008). Fundamentals of Momentum, Heat and Mass Transfer, John Wiley \& Sons, 5th Edition, ISBN 978-0-470-12868-8, New York, USA

Wen, J. \& Li, Y. (2004). Study of Flow Distribution and Its Improvement on the Header of Plate-Fin Heat Exchanger. Cryogenics, Vol. 44, No. 11, (November 2004), pp. 823831, ISSN 0255-2701

Zhang, L.-Z. (2009). Flow Maldistribution and Thermal Performance Deterioration in a Cross-Flow Air to Air Heat Exchanger With Plate-Fin Cores. International Journal of Heat and Mass Transfer, Vol. 52, No. 19-20, (September 2009), pp. 4500-4509, ISSN 0017-9310 


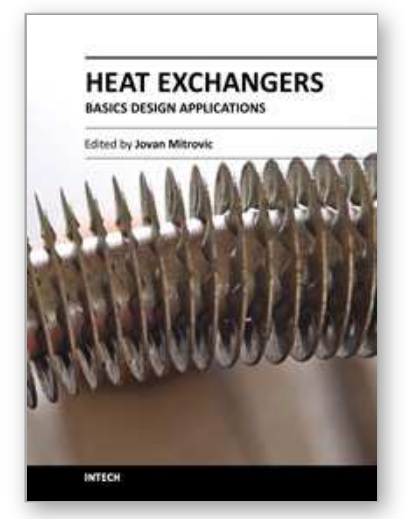

\author{
Heat Exchangers - Basics Design Applications \\ Edited by Dr. Jovan Mitrovic
}

ISBN 978-953-51-0278-6

Hard cover, 586 pages

Publisher InTech

Published online 09, March, 2012

Published in print edition March, 2012

Selecting and bringing together matter provided by specialists, this project offers comprehensive information on particular cases of heat exchangers. The selection was guided by actual and future demands of applied research and industry, mainly focusing on the efficient use and conversion energy in changing environment. Beside the questions of thermodynamic basics, the book addresses several important issues, such as conceptions, design, operations, fouling and cleaning of heat exchangers. It includes also storage of thermal energy and geothermal energy use, directly or by application of heat pumps. The contributions are thematically grouped in sections and the content of each section is introduced by summarising the main objectives of the encompassed chapters. The book is not necessarily intended to be an elementary source of the knowledge in the area it covers, but rather a mentor while pursuing detailed solutions of specific technical problems which face engineers and technicians engaged in research and development in the fields of heat transfer and heat exchangers.

\title{
How to reference
}

In order to correctly reference this scholarly work, feel free to copy and paste the following:

Tomasz Bury (2012). Impact of a Medium Flow Maldistribution on a Cross-Flow Heat Exchanger Performance, Heat Exchangers - Basics Design Applications, Dr. Jovan Mitrovic (Ed.), ISBN: 978-953-51-0278-6, InTech, Available from: http://www.intechopen.com/books/heat-exchangers-basics-design-applications/impact-of-amedium-flow-maldistribution-on-a-cross-flow-heat-exchanger-performance

\section{INTECH}

open science | open minds

\section{InTech Europe}

University Campus STeP Ri

Slavka Krautzeka 83/A

51000 Rijeka, Croatia

Phone: +385 (51) 770447

Fax: +385 (51) 686166

www.intechopen.com

\section{InTech China}

Unit 405, Office Block, Hotel Equatorial Shanghai

No.65, Yan An Road (West), Shanghai, 200040, China

中国上海市延安西路65号上海国际贵都大饭店办公楼 405 单元

Phone: +86-21-62489820

Fax: $+86-21-62489821$ 
(C) 2012 The Author(s). Licensee IntechOpen. This is an open access article distributed under the terms of the Creative Commons Attribution 3.0 License, which permits unrestricted use, distribution, and reproduction in any medium, provided the original work is properly cited. 